\title{
Spatial Estimation of Sika Deer Population Density Distribution
}

\author{
Hiroshi Kondoh $^{* 1}$, Koichi Ikeda*2 and Toru Koizumi*3
}

\begin{abstract}
We estimated the spatial distribution of the sika deer (Cervus nippon) population density in areas around Mt. Hiko in Fukuoka Prefecture, Japan. The data comprised pellet counts in 86 plots from February to April 1999 and from November 1999 to March 2000. Taking this to correspond to the population density in the plots, the sika deer population density was mapped using a kriging interpolator. Five semivariograms were examined in a geographic information system (GIS): spherical, circular, exponential, Gaussian, and linear with sill models. We used the Akaike Information Criterion (AIC) and the Bayesian Information Criterion (BIC) to select the appropriate semivariogram model. The spherical model produced the smallest values in both the AIC and BIC. The ordinary kriging interpolator with the spherical model provided the deer population density at intervals of $50 \mathrm{~m}$. Four distinct high-density areas, in which the deer density exceeded $30 / \mathrm{km}^{2}$, were found around Mt. Kosho and Mt. Hiko. Using independent data for the damage caused by deer and the map of the sika deer density, we estimated the deer densities in all plots where the damage by deer had been checked, and determined the relation between population density and the degree of browsing damage, which is most serious in Fukuoka Prefecture. As the sika deer population density increases, the proportion of damaged plots increases. Of plots with the density exceeding 40 deer $/ \mathrm{km}^{2}$, browsing damage occurred in $83 \%$. This method provides insight into the density of deer over a broad region and, in combination with the information about deer damage, can be applied to give the probability of deer damage.
\end{abstract}

Keywords: browsing damage, distribution map, population density, sika deer (Cervus nippon)

\section{INTRODUCTION}

Damage to planted forests by wildlife has become a serious problem in Japan. Damage by Sika deer alone has accounted for $50 \%$ of the damage to forests in the last 10 years (Forest Agency of Japan, 2003). Sika deer cause damage by browsing, stripping bark, and fraying trees with their antlers. The resulting damage has been considerable in the Kyushu, Kanto, and Chugoku districts of Japan since the late 1980s (Miura, 1999).

To address the problem of sika deer damage in plantation

${ }^{* 1}$ Kyushu Research Center, Forestry and Forest Products Research Institute, Kurokami 4-11-16, Kumamoto, 860-0862, Japan

${ }^{* 2}$ Fukuoka Prefecture Forest Research and Extension Center, Toyota-1438, Yamamoto, Kurume, Fukuoka 839-0827, Japan

${ }^{* 3}$ Forestry and Forest Products Research Institute, Matsunosato 1, Tsukuba 305-8687, Japan forests, the Government of Japan amended the Wildlife Protection and Hunting Law in 1999. A new planning system, the Specified Wildlife Conservation and Management Plan, aims to sustain long-term stable wildlife populations and to promote co-existence between humans and wildlife (KAMIKAWA, 1999; Wildlife Management Workshop of Japan, 2001).

Although browsing damage by sika deer to planted seedlings has been reported in various regions of Japan (Li et al., 1996; Japan Wildlife Research Center, 1998; ToKIDA, 1998; UEYAMA, 1998; Or et al., 2001; MuRAKAmi et al., 2004), few reports have examined the relation between the sika deer density and the extent of the degree of damage. The obvious way to study the relationship is to measure the sika deer density and degree of damage in the same plots. But there is a problem. In Japan, especially western Japan, the pellet-count method is widely used to estimate the sika deer population density. This method assumes that all pellets are decomposed mainly by dung beetles. However, ENDO (2001) found that fecal pellets on bare fields disappeared abruptly in all seasons due to rainfall. Estimates on bare fields may therefore underestimate the true density. IKEDA (2005) also stated that bare fields and young plantations are unsuitable for sika deer 
population surveys. Estimation of the density in an open environment from the density in neighboring forested habitats is not a resolved.

To tackle this issue, we applied an interpolation method of the Geographical Information System (GIS) to our data to map the sika deer population density. We then estimated the deer density distribution on young plantations and analyzed the relation between the density and browsing damage.

\section{MATERIALS AND METHODS}

Study Area

The study areas include recognized sika deer habitats surrounding Mt. Hiko in Fukuoka Prefecture, Japan (Fig. 1).
The area was approximately $1130.3 \mathrm{~km}^{2}$. The deer range was determined from a questionnaire conducted in 1995 by the government of Fukuoka Prefecture, which hunters were asked about hunting places and signs of sika deer, such as footprints (IKEDA, 2001).

The area ranges in elevation from $0-1200 \mathrm{~m}$ above sea level. The boundary between Fukuoka Prefecture and Oita Prefecture is the Hiko Mountains, a cordillera centered on Mt. Hiko. In winter, the peak of Mt. Hiko is often covered by snow to a depth of more than $50 \mathrm{~cm}$. Below $750 \mathrm{~m}$ the vegetation is evergreen broad-leaved forest; above $750 \mathrm{~m}$ there is a zone of deciduous broad-leaved forest.

Fig. 2 shows the vegetation in the study area. The data derive from the 5th National Survey of the Nature Conservation Bureau (1999), running from 1994 to 1998.

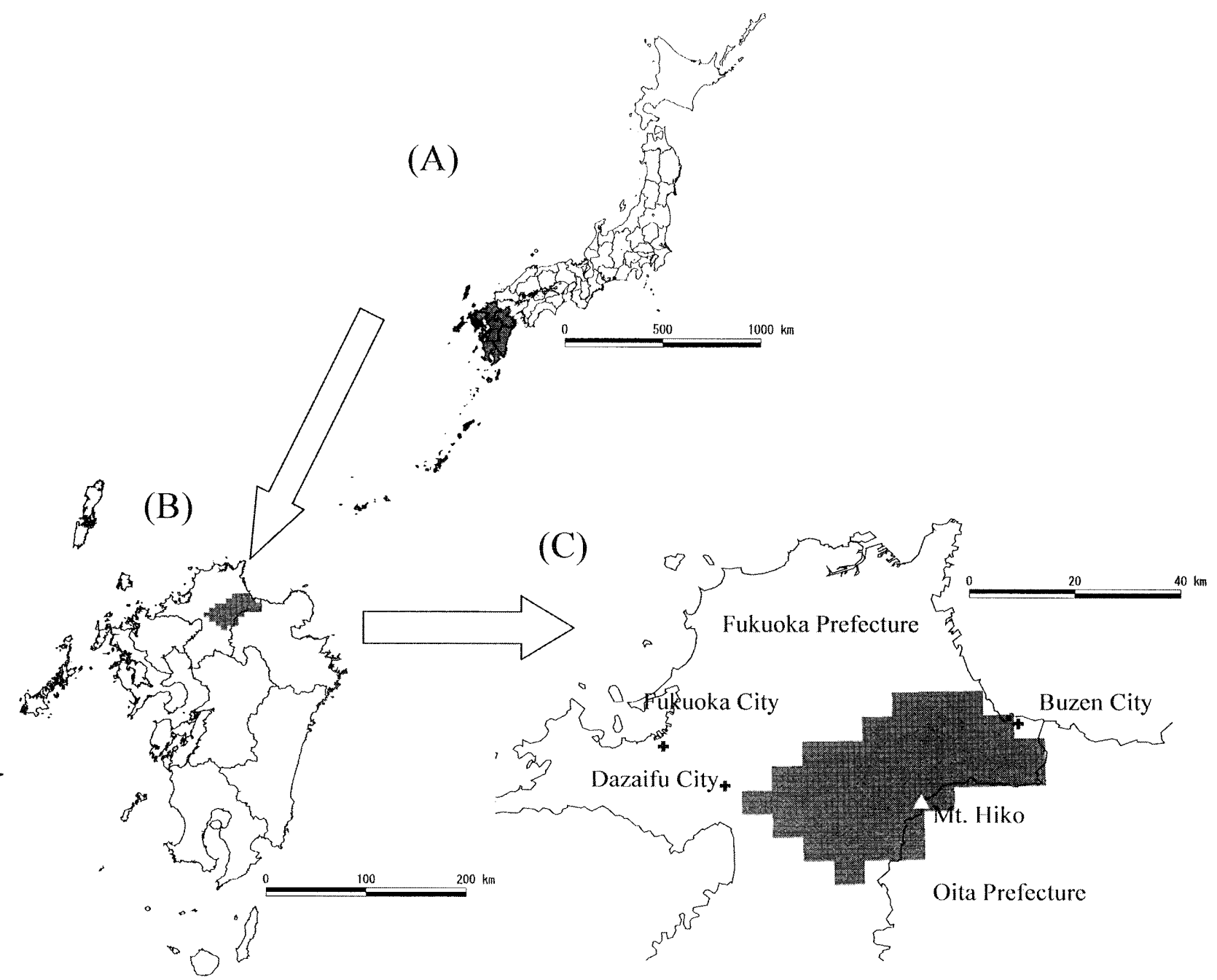

Fig. 1 Study area around Mt. Hiko in Fukuoka Prefecture, Japan. (A) Solid lines show the borders between Japanese prefectures (Kyushu district is the gray zone.) (B) Kyushu district. Solid lines show the borders between prefectures. The study area is the gray zone. (C) Fukuoka Prefecture. Solid lines show the borders between prefectures, and the study area is indicated by the gray zone. 


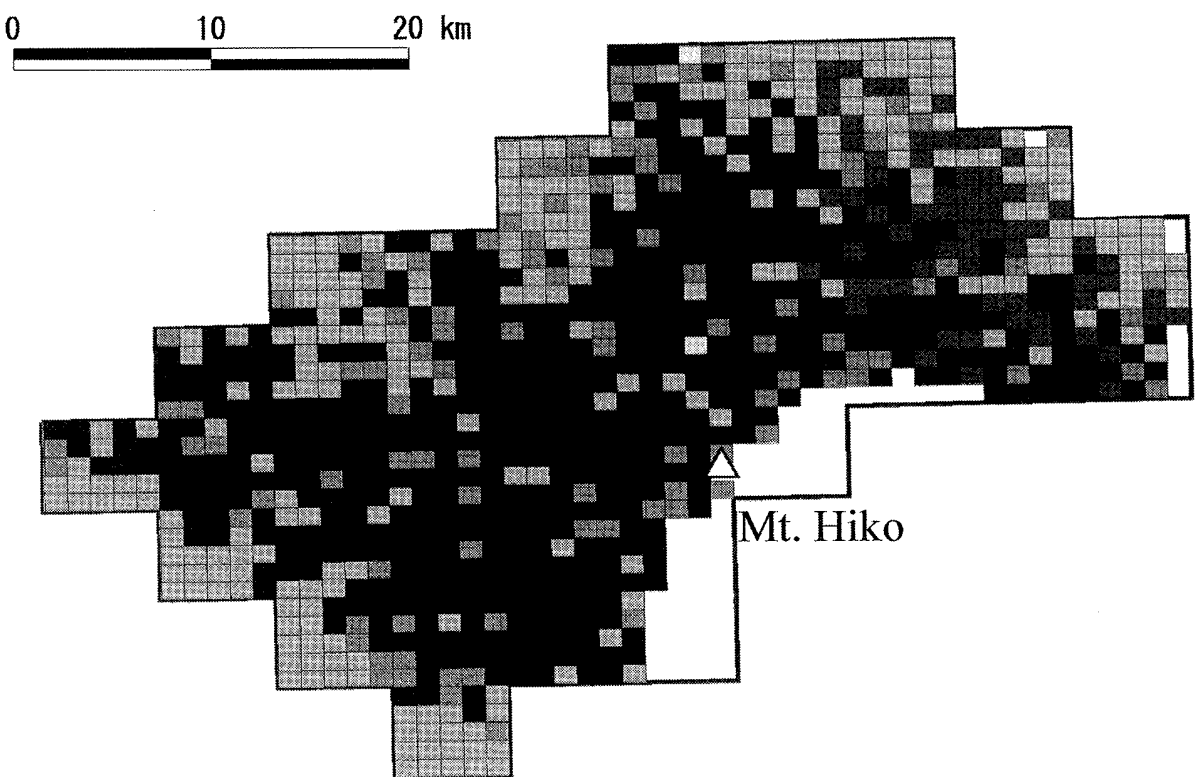

Fig. 2 Vegetation distribution in the study area. indicates plantation of Sugi

(Cryptomeria japonica D. Don) or Hinoki (Chamaecyparis obtuse End1.).

indicates pine (Pinus densiflora Siebold et Zucc. or Pinus thunbergii Parl.).

indicates broad-leaved forest and grassland.

indicates urban land.

indicates cut-over land.

Table 1 Overview of the sika deer population density survey and the damage survey

\begin{tabular}{lll}
\hline & Sika deer population density survey & Damage survey \\
\hline Survey year & from fiscal 1998 to 1999 & from fiscal 1997 to 1999 \\
Number of survey plots & 86 plots & $\begin{array}{l}\text { 1144 plots } \\
\left.(1142 \text { plots were available })^{\mathrm{a}}\right)\end{array}$ \\
Method establishing of survey plot & $\begin{array}{l}\text { set up randomly in the third area mesh } \\
\text { (about 1 kilometer square) }\end{array}$ & $\begin{array}{l}\text { planted forest up to 5 years after planting } \\
\text { Inquirer }\end{array}$ \\
\hline
\end{tabular}

${ }^{\text {a }} 2$ plots were out of the study area.

Plantations of Sugi (Cryptomeria japonica D. Don) and Hinoki (Chamaecyparis obtuse End1.) occupy 53.3\% of the forest. Pine (Pinus densiflora Siebold et Zucc. or Pinus thunbergii Parl.) covered 6.7\%. Broad-leaved forest and grassland, including orchard, bamboo forest, covered $11.2 \%$. Urban land was taken to include residential neighborhoods, playgrounds, industrial areas, dry fields and rice paddies, and comprised $28.7 \%$. The area of cut-over land was $0.01 \%$.

Estimation of Sika Deer Population Density

The sika deer population density was surveyed according to pellet-count, from February to April 1999 and from November 1999 to March 2000. The survey plots were chosen randomly in Basic Grid Squares, according to Announcement No.143 of the Administrative Management Agency of Japan on July, 12, 1973. The survey plot was located at least one plot on each municipality in this study area (IKEDA 2001). Based on the Basic Grid Squares, 86 plots around Mt. Hiko were selected for the deer population survey, as outlined in Table 1. Fig. 3 shows the sika deer survey plots.

In forest in Kyushu district, evergreen trees grow naturally and visibility is poor. It is impractical to count the number of sika deer among mixed evergreen trees. A pellet- 


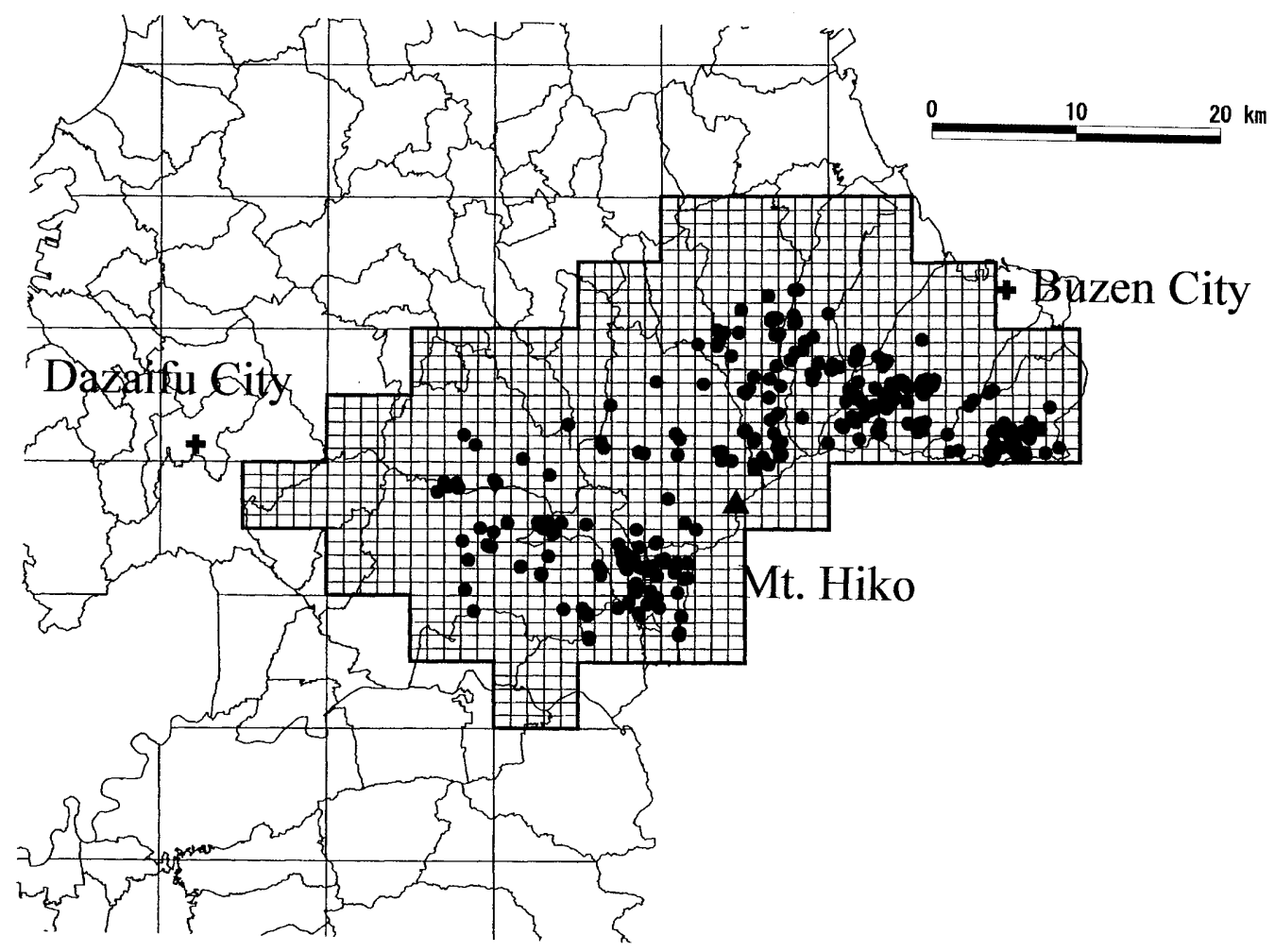

Fig. 3 Distribution of sika deer population density survey plots. Black circles show sika deer population density survey plots. The subdivided area bounded by the heavy line indicates the study area. The fine grid inside the study area indicates Basic Grid Squares (Third Area Partition). Parallel thin lines outside the study area show the Secondary Area Partition. Boundaries between municipalities are also shown.

count method was therefore used to estimate the sika deer population density.

In the pellet count method used in this study, three surveyors were allocated at intervals of 10 meters in the survey plot. The surveyors placed $1 \mathrm{~m}$-square-shaped frames at 10-meter intervals, and counted the number of sika deer pellets retaining their original shapes in the frame after taking out the litter layer. They moved linearly, and counted the number of pellets in a $1 \mathrm{~m}$-square-shaped frame every 10 meters. NisHisHITA (1999) recommended that the survey area should exceed $110 \mathrm{~m}^{2}$, to reduce errors in pellet counts to small levels. The number of $1 \mathrm{~m}$-square areas at a survey plot therefore exceeded 110 .

The density was calculated using the formula derived by IWAMOTO et al. (2000):

$$
N=\frac{f^{\prime}}{\beta\left(\sum_{i=1}^{T} h_{t} e^{-\sum_{i=1}^{t} c_{i i}}\right)}
$$

where:

$N$ is sika deer population density (deer $/ \mathrm{km}^{2}$ ) $f^{\prime}$ is number of pellets found in the survey $\beta$ is rate at which pellets were found $T$ is backdating period (month)

$h_{t}$ is number of pellets defecated by one deer $t$ months ago

$c_{t i}$ is disappearance rate of pellets deposited t months ago and exposed over i months

IWAMOTO et al. (2000) state that the disappearance rate $\left(\mathrm{c}_{t i}\right)$ can be calculated from the atmospheric temperature in a plot when the rate was not measured directly. Backdating period of $T$ was 100 months (IwAMOTO et al., 2000). The temperature of the survey plot was estimated using an adjustment value of $-0.6^{\circ} \mathrm{C}$ per $100 \mathrm{~m}$ of vertical elevation from the temperature recorded at the nearest meteorological station.

\section{Sika Deer Damage Survey}

The deer damage survey in Fukuoka Prefecture was conducted in private forests from 1997 to 1999, focusing on the area around Mt. Hiko. The survey was conducted during weeding operations (involving plantation stands up to 5 years old); and it recorded data such as plant species, years after planting, type of damage, proportion of damaged 


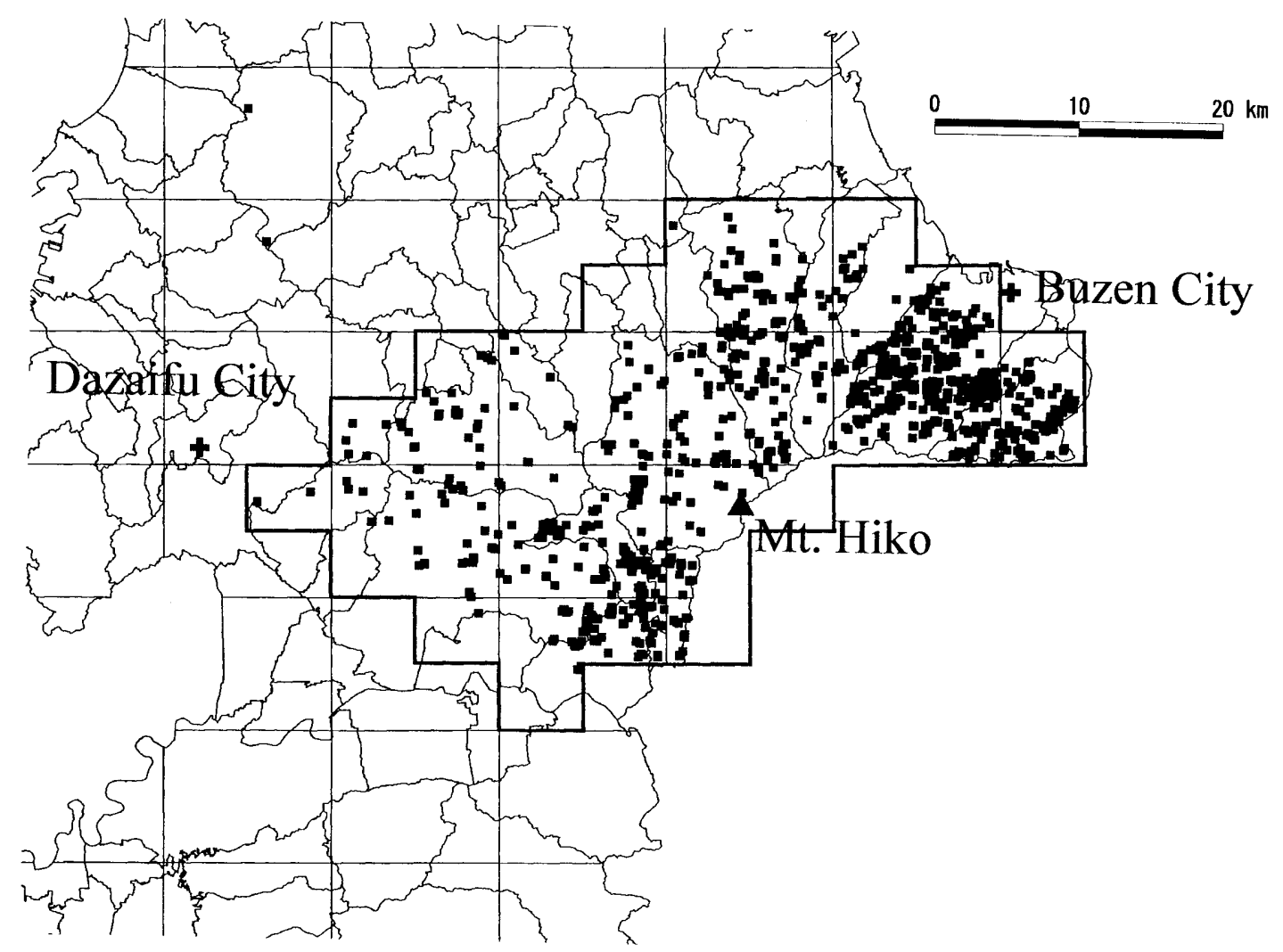

Fig. 4 Sika deer damage survey plots (black squares). The area framed by the heavy line indicates the study area. The large grid shows the Secondary Area Partition. Boundaries between municipalities are also shown.

trees, damage intensity on each plantation tree, and the presence/absence of damage prevention measures (e.g. fences and repellents). Table 1 gives an overview of the deer damage survey. The damage survey plots are shown in Fig. 4.

\section{Method of Estimation of the Sika Deer Population Density}

YABE et al. (2001) estimated that the home range of a single sika deer in the central mountains of Kyushu Island varied between 34-201 ha, which is less than elsewhere in Japan (YABE, 1995; OCHIAI et al., 1996; TADO et al., 1997; MAEJI et al., 2000). ENDo et al. (1996) stated that mean home range sizes ranged from 3.0 to 3.6 ha on Nozaki Island in the Goto Archipelago, Nagasaki Prefecture. Based on the study on Nozaki Island, the home range in southern Japan might be smaller than in other districts of Japan, although this result might be due to the spatial restriction on the island and the high productivity of Zoysia-type grasslands (SHIGEMATSU et al., 1994). This small home range indicates that the deer in this region are sedentary and their density structure is relatively stable, as seen in the population in Miyazaki Prefecture (Japan Wildlife Research Center, 1998).

Since the population density survey plots were discrete, we applied the ordinary kriging interpolator to our database of population density survey locations and population densities (WACKERNAGEL, 1995; MASE et al., 2001). This method was used to interpolate data from discrete survey plots into a map of the whole habitat. The kriging interpolator uses parameter estimation based on the semivariogram model. The semivariogram is a statistic used to understand the relation between distance and the variance of the distance for the data.

The interpolation interval was $50 \mathrm{~m}$, which represents the approximate edge distance of a well-rounded forest compartment in Fukuoka Prefecture (Forest Planning Department of the Forest Erosion Control Division of Fukuoka Prefecture, 2001). For the spatial data analyses (e.g., drawing the population density distribution maps), we used ArcView 3.2a (ESRI Inc.) and Spatial Analyst (an extension of ArcView). For statistics analyses, SPSS (SPSS Inc.) was used.

\section{RESULTS}

Estimating the Distribution of the Sika Deer Population

The semivariogram is calculated from the sika deer population density database according to the following 
equation.

$$
r(h)=\frac{1}{2 n} \sum_{i=1}^{n}\left(Z\left(x_{i}\right)-Z\left(x_{i}+h\right)\right)^{2}
$$

where :

$h$ is an arbitrary distance ( referred to as the 'lag' in online manual in the GIS software)

$n$ is the number of pairs of sample points (in particular, the sika deer population density survey plots) separated by $h$

$Z$ is the attribute value (in particular, sika deer population density)

$r(h)$ is the calculated value of the semivariogram at distance $h$

MASE et al. (2001) called the Eq. [1] the empirical semivariogram.

The value of $h$ is referred to as the lag for the kriging interpolator. In this study, $h$ was $4399 \mathrm{~m}$, which was the maximum distance between a pair of the nearest sika deer population density survey plots. The reason why $h$ was the maximum distance between a pair of the nearest density survey plots was $n>0$ on Eq. [1].

The semivariogram calculated with Eq. [1] is modeled by fitting a theoretical function. In GIS software, spherical, circular, exponential, Gaussian, and linear with sill models were used to model the semivariogram. Below are the equations of the semivariogram models (MASE et al., 2001).

Spherical model

$r(h ; \theta)= \begin{cases}\theta_{0}+\theta_{1}\left(\frac{3 h}{2 \theta_{2}}-\frac{1}{2}\left(\frac{h}{\theta_{2}}\right)^{3}\right), & 0<h \leq \theta_{2} \\ \theta_{0}+\theta_{1}, & h>\theta_{2} \\ 0, & h=0\end{cases}$

Circular model

$r(h ; \theta)= \begin{cases}\theta_{0}+\theta_{1}\left(1-\frac{2}{\pi} \cos ^{-1}\left(\frac{h}{\theta_{2}}\right)+\sqrt{1-\frac{h^{2}}{\theta_{2}^{2}}}\right), & 0<h \leq \theta_{2} \\ \theta_{0}+\theta_{1}, & h>\theta_{2} \\ 0, & h=0\end{cases}$

Exponential model

$r(h ; \theta)= \begin{cases}\theta_{0}+\theta_{1}\left(1-\exp \left(\frac{-h}{\theta_{2}}\right)\right), & h>0 \\ 0, & h=0\end{cases}$

Gussian model

$r(h ; \theta)= \begin{cases}\theta_{0}+\theta_{1}\left(1-\exp \left(\frac{h^{2}}{\theta_{2}{ }^{2}}\right)\right), & h>0 \\ 0, & h=0\end{cases}$
Linear with sill model

$r(h ; \theta)= \begin{cases}\theta_{0}+\theta_{1} h, & h>0 \\ 0, & h=0\end{cases}$

Where :

$\theta$ denotes model parameters $\left(\theta=\left[\theta_{0}, \theta_{1}, \theta_{2}\right]\right)$

These models are described (GRAAF et al., 2003):

Spherical model: this calculates the semivariogram as a modified quadratic function for which, at some distance, pairs of points will no longer be auto correlated and the semivariogram reaches an asymptote.

Circular model: uses a circular neighbourhood search model with a paticular radius.

Exponential model: the exponential model is similar to the spherical model in that it approaches the asymptote gradually. However, it differs from the spherical model in the rate at which the asymptote is approached and in the fact that the asymptote is never actually reached.

Gaussian model: the gaussian or hyperbolic model is similar to the exponential, but it assumes a gradual rise for the y-intercept.

Linear with sill model: this model is similar to the linear model except that at some distance pairs of points are no longer auto correlated and the semivariogram reaches an asymptote.

To select the appropriate semivariogram model, we used the Akaike Information Criterion (AIC) and the Bayesian Information Criterion (BIC). The AIC can be used to select the most appropriate model from a set of models (SAKAMOTO et al., 1983; SuZUKI, 1995). It tends to select the model having the most parameters (FukuI, 2004). To mitigate this tendency, the BIC was also calculated.

Table 2 shows the AIC and BIC for each model. The spherical model produced the smallest values of both AIC and $\mathrm{BIC}$, so that we adopted this model for execution of the interpolator. Fig. 5 shows the density distribution of the sika deer population using the ordinary kriging interpolator with the spherical model.

Fig. 6 shows a histogram of the deer density. The proportion of the low-density area $\left(0-10 \mathrm{deer} / \mathrm{km}^{2}\right)$ exceeded $50 \%$ of the total area. The area below $20 \mathrm{deer} / \mathrm{km}^{2}$ was approximately $90 \%$, and the proportion of high-density area, exceeding 30 deer $/ \mathrm{km}^{2}$, was above $5 \%$. 
Table 2 Semivariogram and Information Criterion. AIC denotes Akaike Information Criterion; BIC is Bayesian Information Criterion.

\begin{tabular}{cccccc}
\hline & Spherical model & Circular model & Exponential model & Gaussian model & Linear with sill model \\
\hline AIC & 109.64 & 109.66 & 121.38 & 120.18 & 109.69 \\
BIC & 110.23 & 110.25 & 121.97 & 120.77 & 110.28 \\
\hline
\end{tabular}

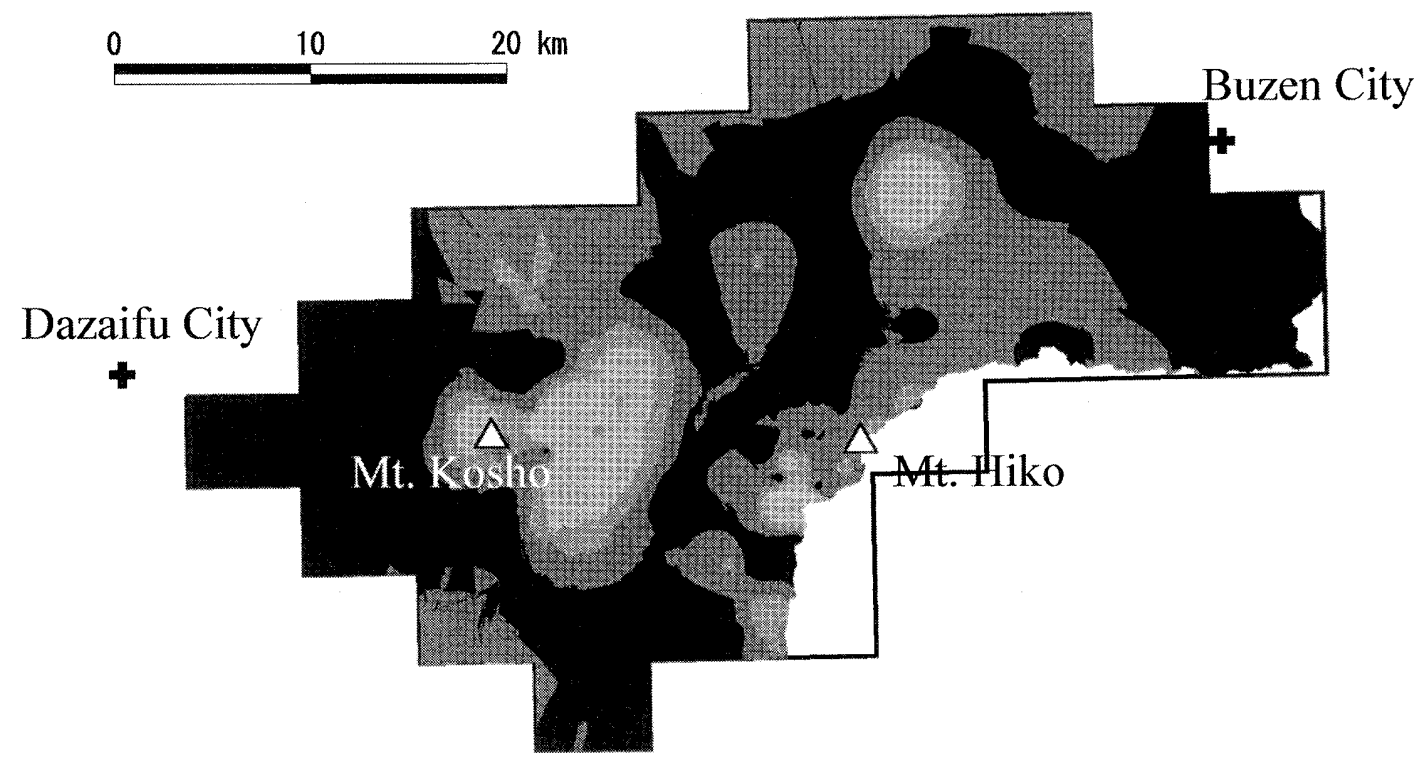
Fig. 5 Kriging interpolation of the sika deer population density using the spherical model. $\quad$ indicates $0-10$ deer population density per $1 \mathrm{~km}^{2}$. indicates $10-20 \mathrm{deer} / \mathrm{km}^{2}$. indicates more than 30 deer $/ \mathrm{km}^{2}$. The area framed by the heavy line is the study area.

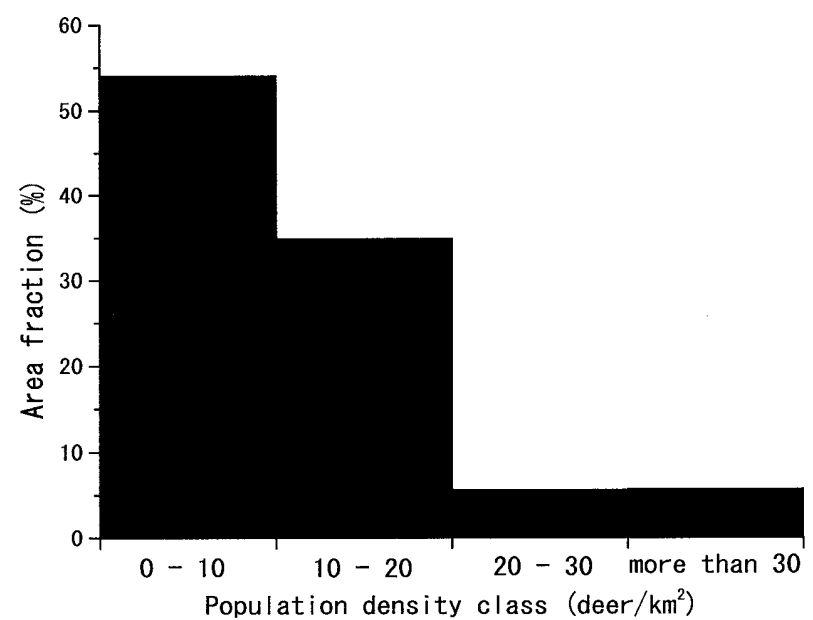

Fig. 6 Histgram of the sika deer population density class. The study area was approximately $1130.3 \mathrm{~km}^{2}$.
Relation between Sika Deer Population Survey Plots and Damage Survey Plots

Sika deer cause damage by browsing, stripping bark, and fraying trees with their antlers. IKEDA (2001) stated that browsing damage is worst in Fukuoka Prefecture. Of the plots where deer damage was recorded, browsing damage was responsible for $95 \%$, whereas the proportion of plots with stripped bark and frayed trees was only $5 \%$.

Table 3 gives on the sika deer damage survey. Sika deer damage was surveyed on 1144 plots. There were 369 damaged plots, which comprised $32.3 \%$ of all damage survey plots. In the damage survey, 1087 plots (95.0\%) were planted with Sugi (Cryptomeria japonica D. Don) or Hinoki (Chamaecyparis obtuse Endl.), which is the main planted tree in Japan. Uniform stands planted Sugi or Hinoki comprised 856 (74.8\%).

96 plots in the survey were equipped with sika deer damage prevention measures, either sika deer repellent or a guard fence. Data from 44 plots were eliminated from the 
Table 3 Overview of sika deer damage survey

\begin{tabular}{|c|c|c|c|c|c|c|c|}
\hline & \multicolumn{3}{|c|}{ Number of damaged plots } & \multicolumn{3}{|c|}{ Number of non-damaged plots } & \multirow[b]{2}{*}{ sum } \\
\hline & $\begin{array}{c}\text { Nonexistence of } \\
\text { protection measures }\end{array}$ & $\begin{array}{c}\text { Existence of } \\
\text { protection measures }\end{array}$ & Unknown & $\begin{array}{l}\text { Nonexistence of } \\
\text { protection measures }\end{array}$ & $\begin{array}{c}\text { Existence of } \\
\text { protection measures }\end{array}$ & Unknown & \\
\hline \multicolumn{8}{|l|}{ Uniform stand } \\
\hline Sugi (Cryptomeria japonica D. Don) & 50 & 7 & & 103 & 13 & 1 & 174 \\
\hline Hinoki (Chamaecyparis obtusa Endl.) & 168 & 36 & 1 & 451 & 24 & 2 & 682 \\
\hline Kunugi (Quercus acutissima Carruth.) & 2 & & & 24 & 1 & & 27 \\
\hline Keyaki (Zelkova serrata Makino) & 10 & & & 2 & & & 12 \\
\hline Kaede (Acer palmatum Thunb.) & & & & 1 & & & 1 \\
\hline $\begin{array}{l}\text { Yamazakura } \\
\text { (Cerasus jamasakura H. Ohba) }\end{array}$ & 1 & & & 1 & & & 2 \\
\hline \multicolumn{8}{|l|}{ Mixd stand } \\
\hline $\begin{array}{l}\text { Sugi (Cryptomeria japonica D. Don) } \\
\text { Hinoki (Chamaecyparis obtusa Endl.) }\end{array}$ & 64 & 7 & & 99 & 4 & 1 & 175 \\
\hline $\begin{array}{l}\text { Sugi (Cryptomeria japonica D. Don) } \\
\text { Keyaki (Zelkova serrata Makino) }\end{array}$ & 2 & & & 1 & & & 3 \\
\hline $\begin{array}{l}\text { Sugi (Cryptomeria japonica } \text { D. Don) } \\
\text { Hinoki (Chamaecyparis obtusa Endl.) } \\
\text { Keyaki (Zelkova serrata Makino) }\end{array}$ & & 2 & & & & & 2 \\
\hline $\begin{array}{l}\text { Sugi (Cryptomeria japonica D. Don) } \\
\text { Keyaki (Zelkova serrata Makino) } \\
\text { Yamazakura } \\
\quad \text { (Cerasus jamasakura } \text { H. Ohda) }\end{array}$ & 2 & & & & & & 2 \\
\hline $\begin{array}{l}\text { Sugi (Cryptomeria japonica D. Don) } \\
\text { Hinoki (Chamaecyparis obtusa Endl.) } \\
\text { Kunugi (Quercus acutissima Carruth.) }\end{array}$ & 1 & & & 14 & & & 15 \\
\hline $\begin{array}{l}\text { Sugi (Cryptomeria japonica D. Don) } \\
\text { Hinoki (Chamaecyparis obtusa Endl.) } \\
\text { Yashabushi } \\
\text { (Alnus firma Siebold et Zucc.) }\end{array}$ & 8 & & & 4 & & & 12 \\
\hline $\begin{array}{l}\text { Hinoki (Chamaecyparis obtusa Endl.) } \\
\text { Icho (Ginkgo biloba L.) }\end{array}$ & & & & 3 & & & 3 \\
\hline $\begin{array}{l}\text { Hinoki (Chamaecyparis obtusa Endl.) } \\
\text { Enju (Sophora japonica L.) }\end{array}$ & & & & 1 & & & 1 \\
\hline $\begin{array}{l}\text { Hinoki (Chamaecyparis obtusa Endl.) } \\
\text { Kunugi (Quercus acutissima Carruth.) }\end{array}$ & & & & 9 & & & 9 \\
\hline $\begin{array}{l}\text { Hinoki (Chamaecyparis obtusa Endl.) } \\
\text { Keyaki (Zelkova serrata Makino) }\end{array}$ & 6 & & & & & & 6 \\
\hline $\begin{array}{l}\text { Hinoki (Chamaecyparis obtusa Endl.) } \\
\text { Sendan (Melia azedarach L.) }\end{array}$ & & & & & 1 & & 1 \\
\hline $\begin{array}{l}\text { Hinoki (Chamaecyparis obtusa Endl.) } \\
\text { Yamazakura } \\
\text { (Cerasus jamasakura } \text { H. Ohba) }\end{array}$ & & & & 1 & & & 1 \\
\hline $\begin{array}{l}\text { Hinoki (Chamaecyparis obtusa Endl.) } \\
\text { Sendan (Melia azedarach L.) } \\
\text { Keyaki (Zelkova serrata Makino) }\end{array}$ & & & & & 1 & & 1 \\
\hline $\begin{array}{l}\text { Icho (Ginkgo biloba } \mathrm{L} \text {.) } \\
\text { Yamazakura } \\
\text { (Cerasus jamasakura } \mathrm{H} \text {. Ohba) } \\
\text { Kunugi (Quercus acutissima Carruth.) }\end{array}$ & & & & 1 & & & 1 \\
\hline $\begin{array}{l}\text { Keyaki (Zelkova serrata Makino) } \\
\text { Icho (Ginkgo biloba } \text { L.) }\end{array}$ & & & & 2 & & & 2 \\
\hline $\begin{array}{l}\text { Keyaki (Zelkova serrata Makino) } \\
\text { Yamazakura } \\
\text { (Cerasus jamasakura } \text { H. Ohba) }\end{array}$ & & & & 3 & & & 3 \\
\hline $\begin{array}{l}\text { Keyaki } \\
\text { (Zelkova serrata } \text { Makino)and so on }\end{array}$ & 1 & & & & & & 1 \\
\hline Unknown Species & 1 & & & 7 & & & 8 \\
\hline Sun & 316 & 52 & 1 & 727 & 44 & 4 & 1144 \\
\hline
\end{tabular}


analysis because protection measures were believed to be responsible for the lack of damage. Consequently, 1100 damage survey plots were used in our analysis.

The sika deer density and damage survey plots were plotted on a topographical map (Fig. 7). This map was based on Fig. 3 and Fig. 4. The sika deer population density survey and damage survey were conducted independently. As stated above, the obvious way to study the relation between the sika deer population density and damage is to measure the sika deer density and degree of damage on the same plots. But a problem is that pellets may decompose differently on bare fields and young plantations (ENDO, 2001, IKEDA, 2005). In addition, the survey timings were different (Table 1). We therefore confirmed the relation between sika deer population density and sika deer damage spatially.

The locations of the population density plots and damage survey plots were treated as point objects. We used a version of the nearest-neighbor distance method to calculate distances between point objects representing the locations of the population density plots and the deer-damaged plots. OKABE $e t$ al. (2000) described the nearest-neighbor distance method as a way to examine the effect of physical objects located in a region upon the distribution of point-like elements over that region. We used only population density plots in which the deer density was nonzero. The average of the nearest distances was obtained. The average nearest distance from undamaged plots was also calculated (Table 4). The average values were then subjected to $t$-tests.

There were 362 damaged and 731 undamaged plots. The average distance from the population density plots to the damaged plots was $\sim 200 \mathrm{~m}$ shorter than the average distance to the undamaged plots. This difference was statistically significant $(p<0.01)$.

Relation between Sika Deer Population Density and Damaged Survey Plots

The $t$-tests showed that the sika deer density survey and the damage survey were correlated. Estimates of deer densities in plots found to be damaged can therefore be used to infer the sika deer density (Fig. 8). Following a computation of the densities in damaged and undamaged plots, the proportion of damaged plots at each increment of $5 \mathrm{deer} / \mathrm{km}^{2}$ is shown as a histogram (Fig. 9). Above $20 \mathrm{deer} / \mathrm{km}^{2}$ the proportion of damaged plots often exceeded $50 \%$.

Fig. 10 shows the relation between the proportion of

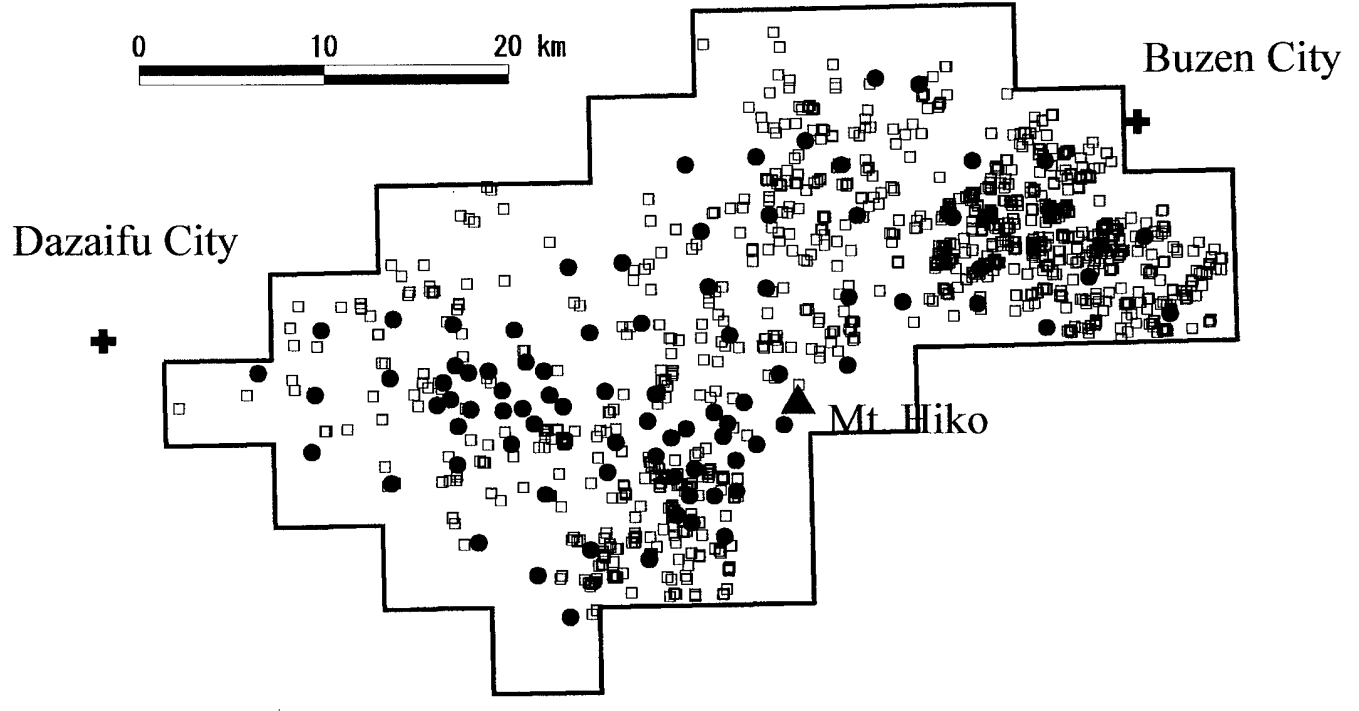

Fig. 7 Distribution of sika deer population density census plots and damage survey plots in the study area. Black circles show sika deer population density survey plots. Squares show sika deer damage survey plots. The study area is framed by the heavy line.

Table 4 Distance from sika deer density survey plot to the nearest damage survey plot.

\begin{tabular}{lcc}
\hline & damaged plots & undamaged plots \\
\hline Total distance to nearest density survey plot $(\mathrm{m})$ & 556595.0 & 1274933.8 \\
Number of plots & 362 & 731 \\
Average distance to nearest density survey plot $(\mathrm{m} / \mathrm{plot})$ & 1537.6 & 1744.1 \\
\hline
\end{tabular}




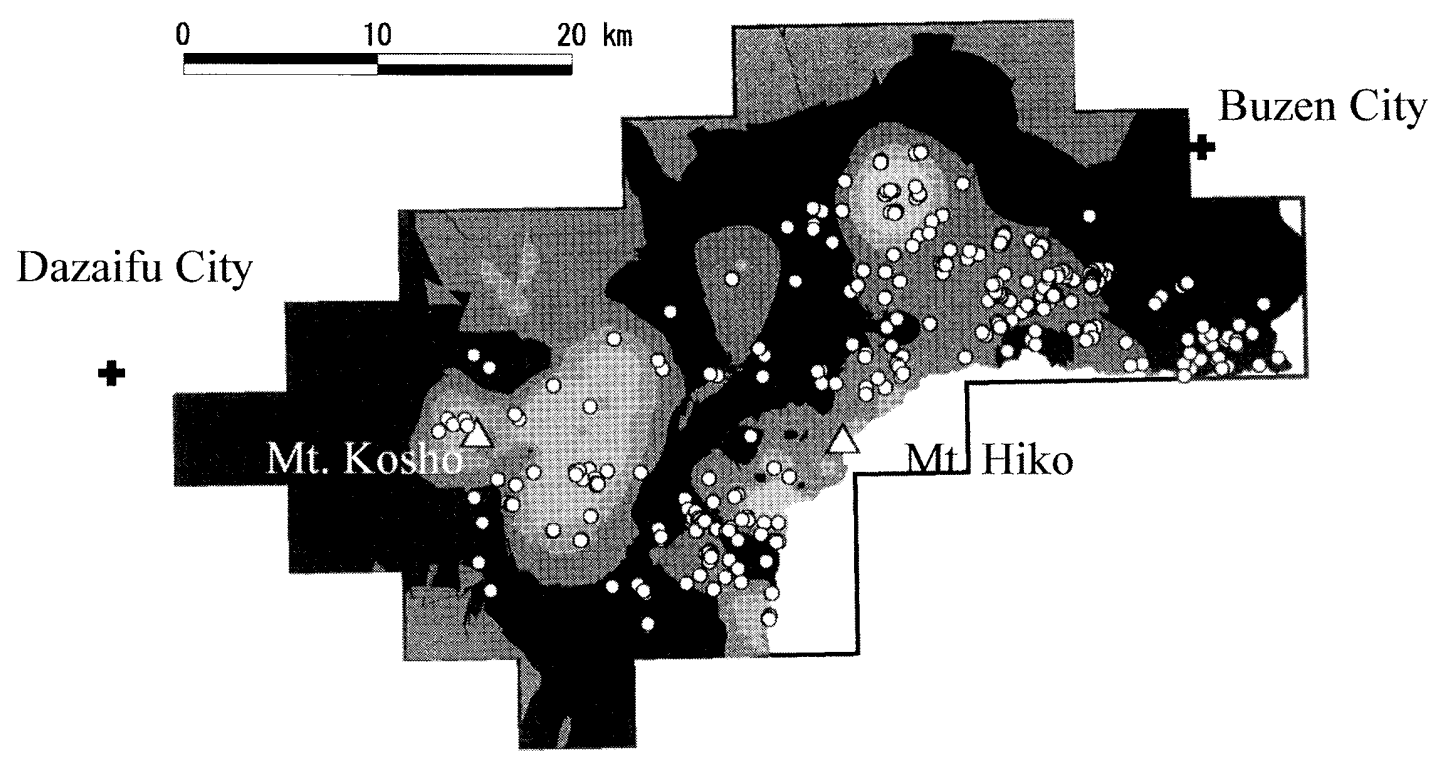

Fig. 8 Sika deer population density overlaid on the damaged survey plots. Circles show damage survey plots damaged by sika deer. indicates $0-10$ deer population density per $1 \mathrm{~km}^{2}$. $10-20$ deer $/ \mathrm{km}^{2}$.

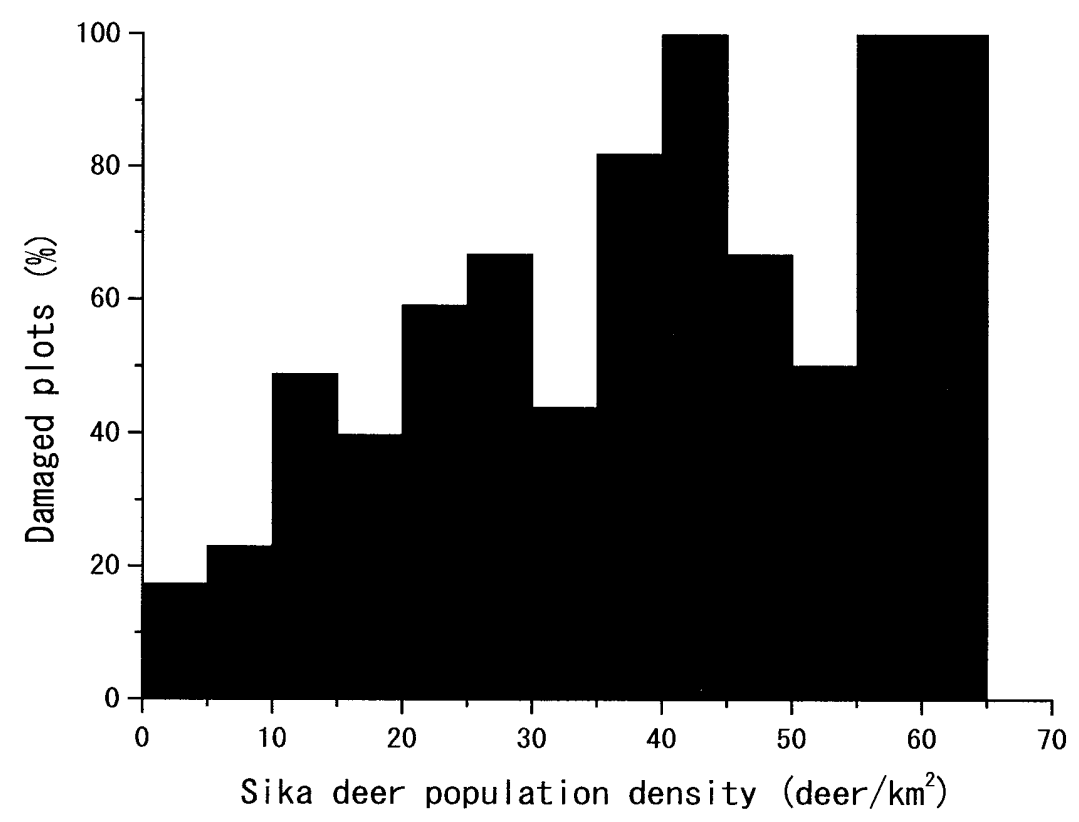

Fig. 9 Fraction of sika deer browsing damage for each population density class. The total number of available damage survey plots in the study area was 1,100 , of which 369 were damaged plots and 731 were undamaged plots without protective measures such as a guard fence. 


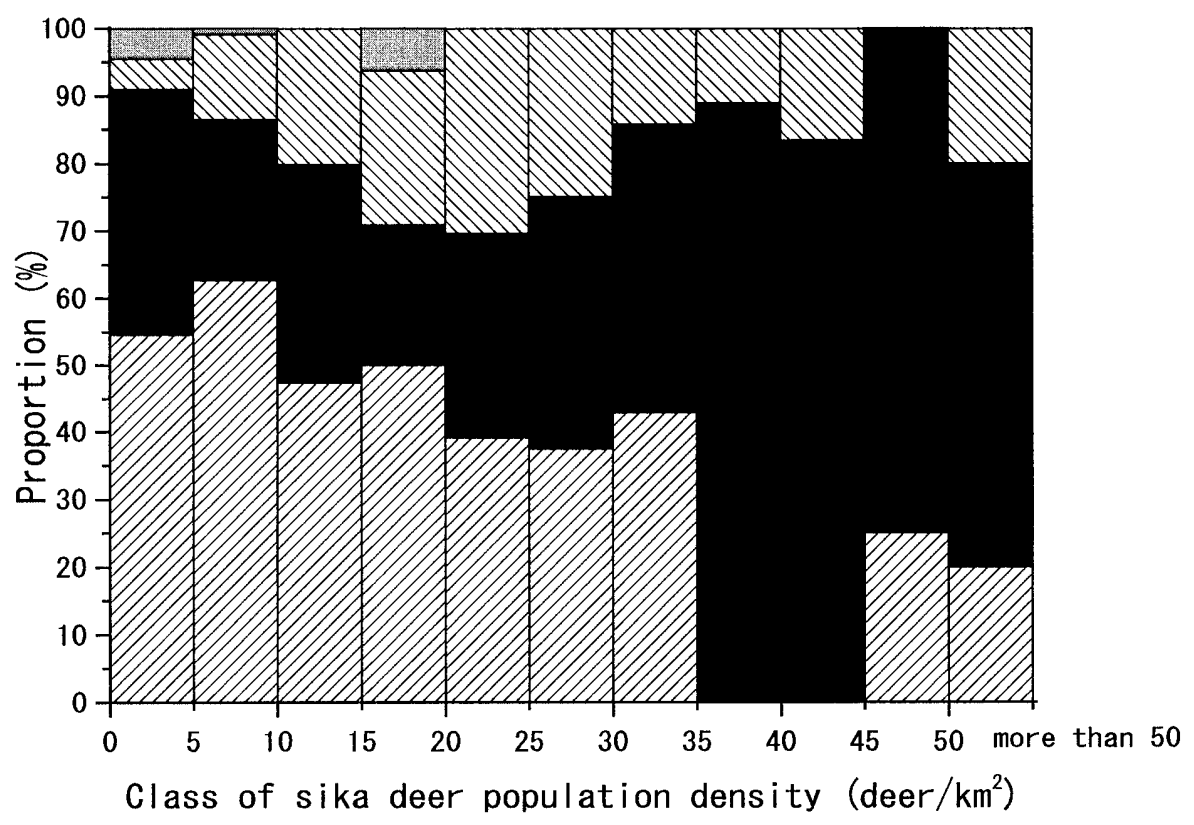

Fig. 10 Fraction of damaged plots on each 5 deer $/ \mathrm{km}^{2}$ class of sika deer population density according to the extent of damaged plantation tree numbers in the plot.

indicates the fraction of plot numbers with less than $30 \%$ of trees damaged (limited damage). Indicates the fraction of plot numbers with between $30 \%$ and $70 \%$ of trees damaged (spread damage). $\mathbf{N}$ indicates the fraction of plot numbers with more than $70 \%$ of trees damaged (extensive damage). fraction of plot numbers with unknown extent of tree damage.

damaged plots at each $5 \mathrm{deer} / \mathrm{km}^{2}$ increment, according to the extent of damaged plantation tree numbers in the damaged plot. The extent of the damage was subdivided into four categories according to the fraction of damaged trees: less than $30 \%$ (hereafter referred to as "limited damage"), between $30 \%$ and $70 \%$ ("spread damage"), more than $70 \%$ ("extensive damage") and unknown extent. Below $10 \mathrm{deer} / \mathrm{km}^{2}$ in Fig. 10, the proportion with limited damage was greater than $50 \%$. Not surprisingly, it tended to decrease as the sika deer density increased.

\section{DISCUSSION}

Previous reports (Environment Agency of Japan, 1989, 1994, 2000; IKEDA, 2001, 2005; Japan Wildlife Research Center, 1998) evaluated the deer density only at points in the survey plots, because there was no method for estimating the density, where no survey had been conducted. This was a severe limitation.

Other reports have shown the density distribution on a grid map with squares more than $1 \mathrm{~km}$ in size (IKEDA, 2001, 2005; Japan Wildlife Research Center, 1998; Nature Conservation Bureau, 1999). In these reports, squares for which there was no information from sika deer population density surveys were shown as 'population unknown' or blank, although square was included in the sika deer habitat.

It is possible to estimate the sika deer population density throughout the habitat by smoothing the point data. The map of sika deer population density in Fig. 5 is derived without conducting a sika deer population density survey.

In Miyazaki Prefecture, an isogram map of the sika deer population density was drawn in 1998 (Japan Wildlife Research Center, 1998). The same report concluded that the population needed to be managed on each sika deer habitat. This suggests that to estimate the deer density accurately requires a large number of survey plots. Although we do not discuss how many plots would be required here, we believe the distribution we obtain is reasonable because the plots are distributed throughout the study area at mean intervals of $2150 \mathrm{~m}$ (minimum $754 \mathrm{~m}$ - maximum 4399m). Additionally, 
referred to the same report, this study area surveyed giving a questionnaire about sika deer to hunters.

The selection of the lag size $h$ in Eq. [1] might have important effects on the empirical semivariogram. ESRI (2001) stated that "When samples were located on a sampling grid, the grid spacing was usually a good indicator for lag size. However, if the data is acquired using an irregular or random sampling scheme, the selection of a suitable lag size is not so straightforward." In Fig 3, the sika deer population density survey plots are not evenly distributed. ESRI (2001) described an empirical method for deciding the lag by multiplying the lag size times by the number of lags, which should be about half of the largest distance between all points. But we could not find an objective method for choosing the lag in previous references. In this study, calculation of lag value adopted as computation method on the maximum distance between a pair of the nearest sika deer population density survey plots. The reason why $h$ was the maximum distance between a pair of the nearest density survey plots was $n>0$ on Eq. [1].

To validate the matching between the observed values from sika deer population density survey and the estimated values using the kriging interpolator, residuals analysis was conducted. A histogram of the residuals is shown in Fig. 11. The mean of residuals was -0.0032 (standard deviation : 0.31997 ), the maximum value of the residuals was 1.2032 , and the minimum was -1.2036 . In Fig. 11, 58\% of all the survey plots were between -0.1 and 0.1 residuals. Given these results, the sika deer population density calculated with the kriging interpolator is estimated accurately. So, in the area surrounding the sika deer population density survey, the accuracy of the sika deer population density might be high. But there were not many survey plots on the peripheral part of the study area. To evaluate the population density distribution with more accuracy than at present, the survey plots should be located evenly.

In Fig. 9, as the sika deer population density increases, the damage proportion generally also increases. Browsing damage occurred in $83 \%$ of plots with more than 40 deer $/ \mathrm{km}^{2}$. Even when the population density exceeded 10 deer $/ \mathrm{km}^{2}$, the proportion of damaged plots reached about $50 \%$. This shows that preventative measures against deer damage, such as constructing a guard fence, should be conducted before planting trees given this density of deer.

The Environment Agency of Japan (1989, 1994, 2000), and HiNo et al. (2003) reported acute destruction of natural vegetation in forests where the deer density exceeds 30.0 deer $/ \mathrm{km}^{2}$. Although recognition of natural forests which have taken a heavy impact of deer is usually difficult, the likely areas can easily be calculated using this approach. The areas in which the density exceeded $30.0 \mathrm{deer} / \mathrm{km}^{2}$ in this study are located east and west of Mt. Kosho, on the southwest of Mt. Hiko, and $13 \mathrm{~km}$ north of Mt. Hiko, totaling $59.1 \mathrm{~km}^{2}$. In these areas, there is a high risk of destruction of natural vegetation by sika deer.

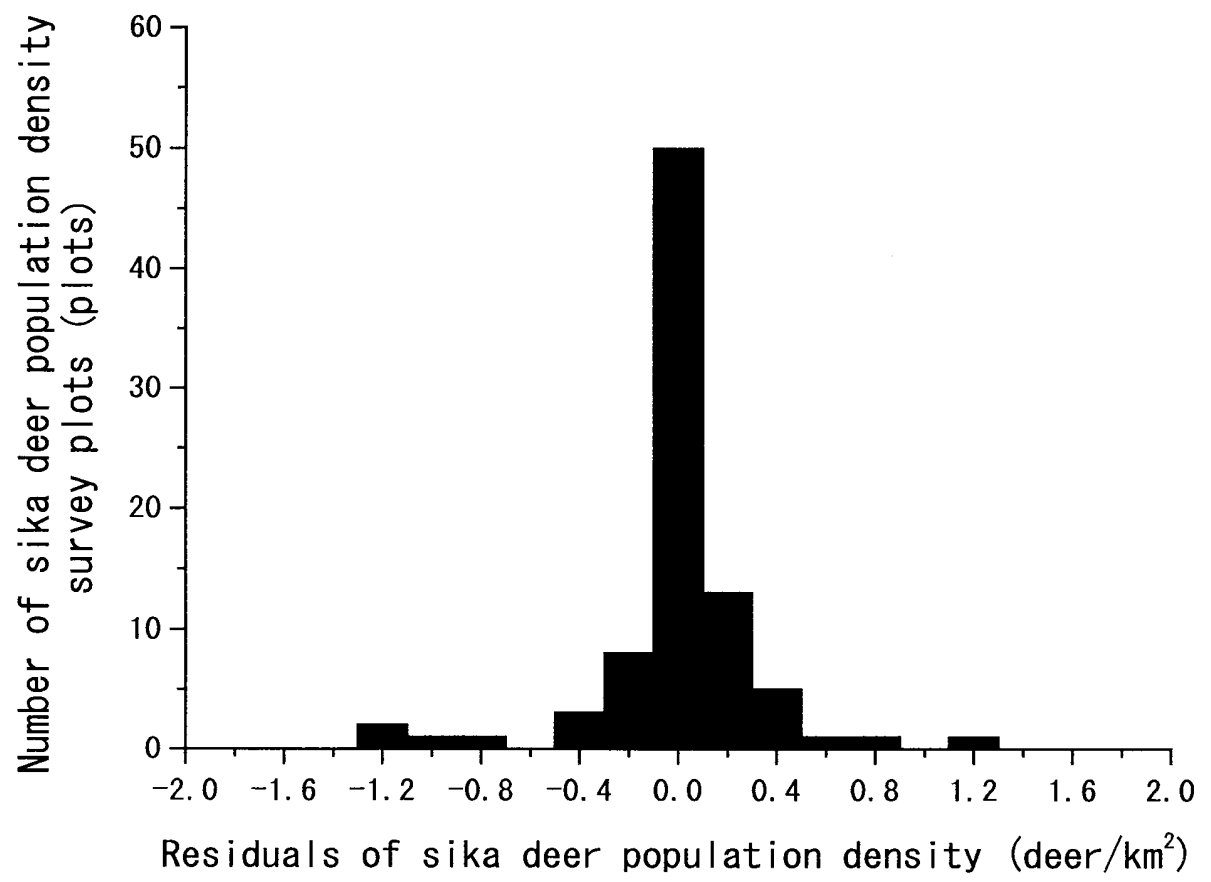

Fig. 11. Histogram of residuals between sika deer population density with the pellet count method and the population density estimated by the kriging interpolator. 


\section{CONCLUSIONS}

This study presents a method for producing a distribution map of the sika deer density from point data for the sika deer population survey taken over a wide area. The map assists in recognizing the high deer density area and analyzing the deer damage. Although the necessary conditions for inferring the sika deer density map should be examined more closely, the present techniques are applicable in other regions, especially in western Japan.

The present study area comprised sika deer habitats surrounding Mt. Hiko in Fukuoka Prefecture. The sika deer range extends to neighboring Oita Prefecture. The sika deer population density surrounding Mt. Hiko might therefore be analyzed if data on the deer in Oita Prefecture are included.

Sika deer caused browsing damage at fairly low population densities. Fig. 9 shows that there were still many undamaged plots in low density areas. Browsing damage is primarily related to the deer density, but other factors such as topography may be considered. More detailed analyses of damage occurrence, including probability distributions for damage, should be considered in future studies.

\section{ACKNOWLEDGMENTS}

We thank Dr. T. Yabe for providing information about sika deer habitats. This study was supported by a Research Grant from the Forestry and Forest Products Research Institute of Japan (Project No. 200001)

\section{LITERATURE CITED}

ENDO, A., and DoI, T., (1996): Home range of female sika deer Cervus nippon on Nozaki Island, the Goto Archipelago, Japan. Mammal Study 21 (1): 27-35

Endo, A., (2001): The Influence of Vegetation Type on Pellet Decay and Pellet Production for Sika Deer (Cervus nippon). Mammalian science 41 (1): 13-22 (in Japanese with an English abstract)

Environment Agency of Japan, (1989): Practical report of Tohi (Picea jezoensis var. hondoensis) forest conservation measures in the Ohdaigahara area from fiscal year 1986 to fiscal year 1988. Environment Agency of Japan, Tokyo, 75pp (in Japanese)

Environment Agency of Japan, (1994): Practical report of Tohi (Picea jezoensis var. hondoensis) forest conservation measures in the Ohdaigahara area from fiscal year 1989 to fiscal year 1993. Environment Agency of Japan, Tokyo, 74pp (in Japanese)

Environment Agency of Japan, (2000): Practical report of Tohi (Picea jezoensis var. hondoensis) forest conservation measures in the Ohdaigahara area from fiscal year 1994 to fiscal year 1998. Environment Agency of Japan, Tokyo, 89pp (in Japanese)

Forest Agency of Japan, (2003): Annual report on trends in forests and forestry. Japan Forest Association, Tokyo, 284pp (in Japanese)

Forest Planning Department of the Forest Erosion Control Division of Fukuoka Prefecture, (2001): Utilization of forestry GIS in forest planning in Fukuoka Prefecture. Rinyajiho564: 44-47 (in Japanese) Fukul, Y.,(2004): Note to $\mathrm{R}^{2}$. Retrieved April 192006 from http://www.geocities.jp/fukuigsim/R2Note.pdf

GRAAF, de G., MARTIN, F., AGUILAR-MANJARREZ, $J$ and JENNESS, J., (2003): Geographic information systems in fisheries management and planning. Technical manual. FAO Fisheries Technical Paper 449, Rome, 182pp

Hino, T., Furusawa, H., Ito, H., Ueda, A., Takahata, Y. and Ito, M., (2003): Forest ecosystem management based on an interaction network in Ohdaigahara. Japanese Journal of Conservation Ecology 8: 145-158 (in Japanese with an English abstract)

IKEDA, K., (2001): Habitat and damage of sika deer in Fukuoka Prefecture. Bull. Fukuoka Pref. For. Res. Ctr. 3: 1-83 (in Japanese)

IKEDA, K., (2005): Management of sika deer (Cervus nippon) in Fukuoka Prefecture. Bull. Fukuoka Pref. For. Res. Ctr. 6: 1-93 (in Japanese)

Iwamoto, T., Sakata, T., NaKazono, T., Kaota, H., Ikeda, K., NishishitA, Y., TOKIDA, K. and DoI, A., (2000): Improvement of the pellet count method for the estimation of sika deer density. Mammalian Science 40 (1): 1-17 (in Japanese with English abstract)

Japan Wildlife Research Center, (1998): The sika deer management plan in Miyazaki Prefecture, Tokyo, 62pp (in Japanese)

KamiKaWA, K., (1999): Overview of revisions to the Wildlife Protection and Hunting Law. Forest Pests 48(10): 12-14 (in Japanese)

Li, Y., Maruyama, N., Koganezawa, M. and Kanzaki, N., (1996): Wintering range expansion and increase of sika deer in Nikko in relation to global warming. Wildl. Conserv. Japan 2(1): 23-35

Maej, I., Kurosaki, T., Yokoyama, S. and Shibata, E., (2000): Home range of sika deer (Cervus nippon) on Mt. Ohdaigahara, central Japan. Nagoya University Forest Science 19: 1-10 (in Japanese with English abstract)

MASE, S. and TAKEDA, J., (2001): Spatial Data Modeling. Kyoritsu Shuppan, Tokyo, 190pp (in Japanese)

MiURA, S., (1999): Wildlife ecology and damage to agriculture and forestry. National Forestry Extension Association of Japan, Tokyo, $174 \mathrm{pp}$ (in Japanese)

Murakami, T., Ikeda, K., Kolzumi, T. and Kondoh, H., (2004): The relationship between age classes obtained from a stand description and the damage to new planting areas by deer browsing. Kyushu J. For. Res. 57: 127-130 (in Japanese with English abstract)

Nature Conservation Bureau, Environment Agency of Japan, (1999): The 5th national vegetation survey report. 346pp (in Japanese with an English abstract)

Nishishita, Y., (1999) Improvement of sika deer (Curvus nippon) population density estimation method on the basis of land use condition on sika deer. Thesis of Miyazaki University, 54pp (in Japanese)

OchiAl, K. and ASADA, M., (1996): Animal tracking by radiotelemetry. In Reports of management for sika deer of Boso peninsula in Chiba Prefecture, IV. Chiba Prefecture, 89pp (in Japanese)

OI, T. and SuzukI, M., (2001): Damage to sugi (Cryptomeria japonica) plantations by sika deer (Cervus nippon) in northern Honshu, Japan. Mammal Study, 26: 9-15 
Okabe, A., Boots, B., Sugihara, K. and Chiu, S. N., (2000): Spatial Tesselations: Concepts and Applications of Voronoi Diagrams, John Wiley \& Sons, New York, 671pp

SAKAmoto, Y., Ishiguro, M. and Krtagawa, G., (1983): Information Statistics. Kyoritsu Shuppan, Tokyo, 236pp (in Japanese)

Shigematsu, Y., OCHIAI, K. and AsADA, M., (1994): Animal tracking by radio-telemetry. In Reports of management for sika deer of Boso peninsula in Chiba Prefecture, II. Chiba Prefecture, 59pp (in Japanese)

SuzukI, G., (1995): Introduction of Statistics Analysis on Information Criterion. Kodansha, Tokyo, 170pp (in Japanese)

TADO, H. and FukUhara, N., (1997): Survey report on habitat flux of wild animals and forest protection measures against wild animals (I). Bull. Yamaguchi Pref. For. Res. Guidance Ctr. 11: 66-75 (in Japanese)

ToKIDA, K., (1998): The present condition of sika deer in the Kyushu district of Japan. Ringyo Gijutsu 680: 27-30 (in Japanese)

UEYAMA, Y., (1998): Measurement of sika deer damage in Hyogo
Prefecture. Ringyo Gijutsu 680: 23-26 (in Japanese)

WACKERnAGel, H., (1995): Multivariate Geostatics. Springer, Germany, 387pp

Wildlife Management Workshop of Japan, (2001): Wildlife Management Guidebook. Japan Forest Association, Tokyo, 418pp (in Japanese)

Yabe, T., Koizumi, T., Endo, A., Seki, S. and Miura, Y. (2001): Home range of sika deer in the central mountains of Kyushu. Kyushu Journal of Forest Research 54: 131-132 (in Japanese)

YABE, T., (1995): A fundamental study on habitat management in relation to wildlife: habitat use of sika deer and a change in the vegetation on Shiretoko Peninsula, Hokkaido. The Research Bulletin of the Hokkaido University Forests 52(2): 115-180 (in Japanese with an English abstract)

(Received 24 August 2006) (Accepted 25 December 2006) 